\title{
JOGOS ADAPTADOS PARA O ENSINO DE FÍSICA
}

\author{
ADAPTED GAMES FOR PHYSICS EDUCATION \\ Adriana da Silva Fontes ${ }^{1}$, Fernanda Peres Ramos ${ }^{2}$, Roseli Constantino Schwerz ${ }^{3}$, Claudete \\ Cargnin $^{4}$ \\ ${ }^{1-4}$ Universidade Tecnológica Federal do Paraná \\ ${ }^{1}$ Departamento de Física, asfontesfis@gmail.com \\ ${ }^{2}$ Departamento Acadêmico de Ambiental, fernandaramos@utfpr.edu.br \\ ${ }^{3}$ Departamento de Física, roselicc@gmail.com \\ ${ }^{4}$ Departamento de Matemática, claucf@gmail.com
}

\section{RESUMO}

Este artigo tem como intenção estimular o uso de jogos didáticos como um possível fomentador no processo de ensino-aprendizagem. O objetivo é compartilhar ações que possam ser aplicadas por professores do Ensino Básico na disciplina de Física. A proposta aqui narrada foi desenvolvida durante a disciplina de Física 1, no curso de Licenciatura em Química em uma Universidade pública. Durante essa atividade foi possível identificar que: (1) os acadêmicos desconheciam a possibilidade de utilizarem jogos didáticos como uma ferramenta coadjuvante para o processo de ensinoaprendizagem; (2) as turmas do Ensino Médio, cujos alunos testaram os jogos, participaram ativamente das aulas e aprovaram o material didático; (3) os professores da rede pública cujos jogos foram apresentados, gostaram muito da ideia e se animaram para adaptar jogos para o ensino de Física. Deste modo, concluímos que os jogos didáticos podem ser utilizados na formação docente e no ensino de Física, além de propormos que, caso o professor não tenha condições de elaborar um jogo, faça adaptações a jogos já existentes.

Palavras-chave: Ensino de Física; Jogos didáticos; Formação inicial de professores.

\begin{abstract}
This article is intended to encourage the use of educational games as a possible developer in the teaching-learning process. The goal is to share actions that can be implemented by basic education teachers in the discipline Physics. The proposal here narrated was developed during the discipline Physics 1, for Chemistry majors in a public university. During this activity were identified: (1) the students were unaware of the possibility of using educational games as a supporting tool for teaching-learning process; (2) classes of high school, whose students tested the games, actively participated in the classes and approved courseware; (3) the public school teachers, whose games were presented, loved the idea and were encouraged to adapt games for teaching Physics. Thus, we conclude that the educational games can be used in teacher education and physical education, and propose that, if the teacher is unable to create a game, he could at least make adjustments to existing ones.
\end{abstract}

Key words: Physical Education; Educational games; Initial training of teachers.

\section{INTRODUÇÃO}

São muitas as dificuldades encontradas no ensino de Física, em especial na rede pública da Educação Básica (Ensino Fundamental e Médio), entre as quais: o 
grande número de alunos em sala de aula; muito conteúdo para um reduzido número de aulas semanais; falta de domínio de conteúdos por parte de alguns professores; falta de didática para ensina-los. Outra falha muito comum no ensino de Física é a de apresentala como um assunto tedioso, um enorme número de problemas ou ainda como um grande conjunto de fórmulas que devem ser decoradas para se obter êxito na resolução de problemas de vestibulares e ENEM (MOREIRA, 1983). Outro ponto muito grave é que muitos alunos oriundos de escolas públicas, principalmente, nunca tiveram aulas práticas/experimentais, seja por falta de laboratório na escola ou por falta de habilidade do professor.

A Física é uma disciplina que necessita de habilidades como abstração, raciocínio, pensamento, reflexão, criatividade, experimentação, dentre outras, o que acaba tornando-a trabalhosa já que nem todos esses aspectos são desenvolvidos durante a formação dos alunos. Essas dificuldades acabam muitas vezes fazendo com que professores tendam a desenvolver as suas aulas utilizando-se de métodos antigos de ensino, que são baseados na transmissão de conteúdos e assimilação através de exercícios. Como reflexo disso tem-se o preconceito dos alunos com relação à disciplina de Física, o que acaba dificultando ainda mais o processo de ensino e tornando o problema cada vez maior (RAHAL; LUZ, 2008).

De acordo com a Resolução $n^{\circ} 2-\mathrm{CNE} / \mathrm{CP}^{1}{ }^{1}$, de 19 de fevereiro de 2002, a carga horária para a organização curricular dos cursos de Formação de Professores da Educação Básica, de Graduação Plena em Nível Superior, em Curso de Licenciatura deverá integralizar um mínimo de 2.800 (duas mil e oitocentas) horas, nas quais a articulação teoria-prática garanta, nos termos dos seus projetos pedagógicos, as seguintes dimensões dos componentes comuns: - 400 (quatrocentas) horas de prática como componente curricular (PCC), vivenciadas ao longo do curso - 400 (quatrocentas) horas de estágio curricular supervisionado a partir do início da segunda metade do curso. - 1.800 (mil e oitocentas) horas de aulas para os conteúdos curriculares de natureza científico-cultural; - 200 (duzentas) horas para as outras formas. Além disso, há que se lembrar que novas Diretrizes Curriculares Nacionais para a formação de Profissionais do Magistério da Educação Básica foram formalizadas através da Resolução 2/2015 CNE/CP, de 01 de julho de 2015, com prazo até julho de 2017 para

\footnotetext{
${ }^{1}$ Conselho Nacional de Educação/ Conselho Pleno
} 
serem aplicadas. A partir desta data, os cursos de Licenciaturas sofrerão ampliação para 3200 horas de aula, sendo 2200 horas de estudo e aprofundamento de conteúdos disciplinares e pedagógicos, mantendo-se às 400 horas de PCC obrigatórias e distribuídas ao longo do curso.

As atividades PCC devem ser distribuídas dentro de algumas disciplinas devendo ser aplicadas desde o início da formação e se estender ao longo de todo o curso. Essas atividades poderão ser organizadas sob a forma de Projetos Integradores, tendo como perspectiva a implementação de seminários de integração e vivências práticas, devendo contemplar um elemento integrador da teoria e da prática ao longo do curso e potencializar ações de formação que evidenciem a característica multiinterdisciplinar do conhecimento (SOUZA NETO; SILVA, 2014).

Nos cursos de licenciatura da $\mathrm{UTFPR}^{2}$, as atividades PCC estão inseridas no interior das disciplinas, para que o futuro professor use os conhecimentos que aprender e se aproprie de experiências em diferentes tempos e espaços curriculares. O princípio metodológico da prática como componente curricular não se resume na discussão de dimensão prioritária na formação do professor, entre teoria e prática. Propõe pensar no processo de construção de sua autonomia intelectual: o professor além de saber e de saber fazer deve compreender o que faz. Tem como finalidade promover a articulação das diferentes práticas numa perspectiva interdisciplinar, destacando o método de observação e reflexão para entender e atuar em situações contextualizadas. Com ênfase nos procedimentos de observação e reflexão, visando à atuação em situações contextualizadas, tendo como objetivo, desenvolver uma análise crítica reflexiva referente à prática escolar no Ensino Básico, confrontando os conteúdos discutidos em sala (UTFPR, 2012).

Essas atividades práticas cooperam para promover diversas possibilidades para o aprendizado significativo. Além de permitir a compreensão de certas teorias, contribui para o desenvolvimento da capacidade cognitiva e do raciocínio científico. E ainda favorece o trabalho em equipe por meio da discussão, da divisão de tarefas e da argumentação lógica. Espera-se com isso, um progresso na elaboração de conceitos e no desenvolvimento da intelectualidade do aluno.

\footnotetext{
${ }^{2}$ Universidade Tecnológica Federal do Paraná
} 
Na disciplina de Física 1, para o $2^{\circ}$ período do curso de Licenciatura em Química são destinadas 10h/a para o desenvolvimento dessa componente (PCC).

\section{UTILIZAÇÃO DOS JOGOS COMO RECURSO PEDAGÓGICO}

Segundo Yamazaki; Yamazaki (2014), os jogos são relevantes no sentido de que se constituem como investimentos alternativos que apontam para mudanças nos métodos de ensino baseados na transmissão e recepção de conteúdos. Porém, devem ser construídos e utilizados por meio de um diálogo com teorias que se mostram relevantes aos comportamentos humanos, pois dessa forma podem desenvolver uma potencialidade para discutir desde questões históricas, epistemológicas e sociológicas até questões que se aproximam do âmbito educacional, como a psicologia e a própria pedagogia. Ao contrário, a falta desse diálogo não permite que se estabeleça comunicação entre as distintas faces do problema da formação do aluno, impossibilitando análises objetivas a fim de melhorar as intervenções didáticopedagógicas.

No ensino de Física, os jogos didáticos podem ser utilizados em sala de aula para: introduzir ou ilustrar aspectos importantes do conteúdo desenvolvido; avaliar a aprendizagem de conceitos; revisar ou sintetizar pontos relevantes do conteúdo.

É uma atividade lúdica que pode ser utilizada pelo professor a fim de proporcionar a participação de todos os alunos, não deixando nenhum para trás, de tal modo que cada aluno se torna agente ativo no processo ensino-aprendizagem. $\mathrm{O}$ jogo também pode ser utilizado para introduzir um conteúdo, de modo mais motivador e interessante para atingir determinados objetivos pedagógicos, sendo uma alternativa para se melhorar o desempenho dos estudantes em alguns conteúdos de difícil aprendizagem (GOMES; FRIEDRICH, 2001).

Devido ao seu caráter lúdico é uma boa alternativa para despertar o interesse dos alunos e com isso as possibilidades de trabalho são muito grandes assim como tende ser a produtividade já que a mediação dos conteúdos pelo professor acaba sendo facilitada (NASCIMENTO, 2010).

Em acordo com Pereira, Fusinato e Neves (2009, p.16), para se construir um bom jogo educativo é necessário dominar os referenciais teóricos do conteúdo implícito 
no jogo, ser capaz de relaciona-los a situações concretas e atuais, pesquisar e avaliar os recursos didáticos favoráveis às situações de ensino-aprendizagem.

Existem vários tipos de jogos, entre os mais utilizados estão os jogos de tabuleiro. Estes consistem de uma placa com desenhos ou marcações na qual peças podem se mover, de acordo com um conjunto de regras pré-estabelecidas. Eles podem ter diferentes números de jogadores e o sucesso deles depende de fatores como sorte e estratégia. Podem ser classificados de diferentes modos, abordando situações da vida real ou nem mesmo apresentar um tema específico. Além de permitir momentos de descontração, eles podem ajudar no desenvolvimento de raciocínio lógico e memória.

Algumas análises já publicadas demonstram que os jogos podem se apresentar como recursos pedagógicos que possuem potencial para contribuir efetivamente no processo ensino-aprendizagem em algumas áreas de ensino, como línguas, matemática e Física (RAMANI, 2008; VIRVOU, 2014; PARIS, 2012; SAVI et al, 2010). Mesquita (2013), por exemplo, afirma que os jogos podem proporcionar momentos de descontração e interação social e, principalmente, contribuir para a melhor compreensão do conteúdo por parte dos alunos. Eles podem ser aplicados para identificar e analisar dúvidas, nível de conhecimento da classe, preconcepções sobre o tema, entre outros. Assim, além de contribuir para a melhor compreensão do conteúdo por parte dos alunos, este recurso também pode auxiliar o professor a identificar os assuntos do conteúdo que precisam ser mais bem trabalhados em sala de aula.

A aplicação de jogos pode ser utilizada em áreas distintas. O que eles nos indicam, portanto, é que há grande potencialidade desses jogos no contexto pedagógico. É uma ferramenta que pode ser utilizada para auxiliar o aluno em seu processo de construção do conhecimento, pois além de ser um novo meio de permitir-lhe interagir com o conteúdo em questão, permite modificar o ambiente da sala de aula. Deste modo, os jogos têm o potencial de tornar a aula mais dinâmica, mais atrativa ao aluno. $\mathrm{O}$ aprendiz possivelmente apresentará maior disposição a aprender, quesito este indispensável para que ocorra a aprendizagem significativa.

Embora inúmeros benefícios sejam disseminados, não se tem conhecimento de jogos educativos na área de ensino de Física disponíveis para a compra, e nem sempre o professor tem tempo ou habilidades para confeccionar um jogo de modo atraente para o aluno. Além disso, na literatura existem ótimos trabalhos a respeito do assunto, porém 
são poucos que apresentam o jogo de modo que o professor possa baixar da internet ou então confeccionar o mesmo, entre os quais cito o de Rahal (2009) para o ensino da termodinâmica; o de Pereira, Altoé e Neves, (2009) “Conhecendo a Física” para o ensino de diversos conteúdos da Física; o de Pereira e Altoé, (2011) para o ensino de Astronomia; a dissertação de Hudson (2010), que nos mostra o jogo "a trilha" para explorar conteúdos de óptica geométrica, e os de Ferreira et al, (2011) que apresenta vários jogos e explora diversos conteúdos de forma muito cuidadosa. Desse modo, esse assunto ainda tem lacunas a serem preenchidas.

Alguns professores não utilizam o jogo didático, apesar de saberem que pode ser um recurso facilitador do processo de ensino-aprendizagem, por vários motivos. Entre eles, falta de tempo para comprar os materiais, para pesquisar e confeccionar o jogo (pesquisar o formato do mesmo) ou para relacionar os conteúdos de Física com o jogo.

Pensando nisso, nossa busca inicial centrou-se em lojas populares como as chamadas "lojas de R $\$ 1,99 "$ (conhecidas em todo o país), cujo número tem crescido muito nos últimos anos. Nesse comércio, bastante diversificado, encontramos vários materiais didáticos. Apoiados nesse ambiente, desenvolvemos uma proposta para incentivar o futuro professor a ter o seu jogo didático.

Existe vantagem em se adquirir um jogo pronto, quando comparamos os casos nos quais o professor necessita construi-lo. Como ele possui o layout e as peças, o professor não precisa gastar tempo para confecciona-los. Além disso, as regras já estabelecidas pelo fabricante também podem ser utilizadas e adaptadas para o fim pedagógico. Diante disto, esse trabalho apresenta alguns dos jogos de tabuleiro existentes no mercado e faz certas adaptações para o uso na disciplina Física, descrevendo suas regras e recursos.

A principal finalidade desta proposta é mostrar aos futuros professores e aos professores que é possível associar o conteúdo trabalhado nas aulas com o jogo didático, sendo esse uma forma alternativa de ensino, pois essa ferramenta pode ajudar nas soluções dos problemas encontrados no ensino de Física, no nível médio (RAHAL; LUZ, 2008). 
De acordo com Yamazaki; Yamazaki (2014), uma das maiores vantagens pedagógicas que o jogo pode proporcionar é a motivação, mas, os jogos devem também proporcionar a aprendizagem; e não somente aprendizagem de conteúdos, mas de noções que dizem respeito à gênese, à possibilidade e à essência do conhecimento, além de valores éticos para a vida em sociedade. Todos esses elementos são importantes para a formação do cidadão para que ele tenha posições críticas para exercer as habilidades e as competências, mencionadas nos cursos de formação de professores.

É importante destacar que nas lojas populares existem jogos como Bingos, Dominós, Jogo da memória, Quebra-cabeça, Batalha Naval, Caça-Palavras, Tabuleiros, entre outros. Os jogos que foram utilizados como modelos e adaptados para esse trabalho foram os jogos de tabuleiro.

O jogo de tabuleiro é, em geral, baseado em perguntas e respostas, onde os jogadores devem percorrer as casas do circuito fechado, cumprindo determinações que algumas casas espalhadas pelo tabuleiro exigem. Vence o jogo, o jogador que primeiro completar o circuito. $\mathrm{O}$ conteúdo das perguntas é relativo à Física que tradicionalmente é abordada nos currículos do Ensino Médio.

\section{DESENVOLVIMENTO}

Esse trabalho foi desenvolvido durante a disciplina de Física 1, como atividade PCC, com 21 dos alunos do curso de graduação em Química (Licenciatura), em uma Universidade Pública na cidade de Campo Mourão, objetivando buscar uma prática que ajudasse na formação e na identidade do futuro professor. Foi dividido em três etapas: na primeira buscou-se fazer um levantamento junto aos acadêmicos sobre as atuais metodologias alternativas no ensino de Física que eles poderiam utilizar em sala de aula visando às necessidades dos alunos para com a disciplina. Após discussões, a professora regente, que é autora deste trabalho, apresentou diversos jogos de tabuleiro, oriundos de lojas populares e desafiou os acadêmicos a adapta-los à disciplina de Física de modo a auxilia-los no processo de ensinar, podendo ser utilizados pelos licenciados com alunos de Ensino Fundamental e Médio. Após duas semanas necessárias para a pesquisa e a adaptação dos jogos, cada grupo, que ficou responsável pela adaptação de um jogo, apresentou em sala de aula, sob forma de Seminário de Integração, seu jogo, suas adaptações e explicou como o professor pode usufruir desse material didático para o 
ensino de conteúdos da disciplina Física. Houve discussões e sugestões a respeito do trabalho.

Os jogos de tabuleiro, oriundos de lojas populares, que foram utilizados como modelos para as adaptações pelos acadêmicos bem como os grupos estão apresentados na tabela 1 .

Tabela 1: Tipos de jogos de tabuleiro e grupos.

\begin{tabular}{|c|l|}
\hline Jogos & Grupo / no de alunos \\
\hline Fazendo compras & Grupo A / 4 \\
\hline O trânsito & Grupo B / 4 \\
\hline Caça ao tesouro & Grupo C / 3 \\
\hline Ilha do tesouro & Grupo D / 5 \\
\hline Dama & Grupo E / 5 \\
\hline
\end{tabular}

A segunda etapa foi a de verificar a aceitação/utilidade dos jogos em turmas do Ensino Médio (EM). Para isso, os jogos foram aplicados, em uma turma de $2^{\circ}$ ano (Física 1) e em uma turma de $3^{\circ}$ ano (Física 2) do ensino técnico, de outra professora da instituição, envolvendo no total 58 alunos ( 29 do $2^{\circ}$ ano e 29 alunos do $3^{\circ}$ ano). Para a avaliação do processo, foi aplicado um aos alunos ao final da aula, cuja síntese está apresentada no próximo item.

A terceira etapa foi a de apresentação dos jogos, como um recurso de apoio em sala de aula a um grupo de 18 professores que lecionam Física em escolas públicas de Campo Mourão e Região durante uma oficina de Física (formação continuada) organizada pela professora regente.

Após a realização das três etapas, na aula seguinte foi dado um feedback para os licenciandos, onde a professora regente apresentou os dados levantados junto aos alunos do EM e aos professores que participaram da oficina.

\section{RESULTADOS E DISCUSSÕES}

Foi identificado junto aos licenciandos em Química que nenhum deles havia tido contato com jogos didáticos para o ensino de Física durante sua vida escolar, e por esse motivo, realizou-se essa atividade como PCC na disciplina de Física 1. 
Em consonância com Legey et al (2012), o jogo educativo pode ser uma metodologia de incentivo aos futuros professores, pois ele permite pesquisar, organizar e inter-relacionar conhecimentos, exercitando a criatividade e o senso crítico.

Os jogos ficaram bastante interessantes. Porém, a professora regente identificou que a maioria não estava rico em detalhes, o que poderia dificultar o resultado esperado, quando aplicado a alunos do Ensino Fundamental, porém, mediante programação, optou-se em aplicá-lo mesmo assim para colher mais sugestões.

\section{JOGO "FAZENDO COMPRAS"}

Um grupo de licenciandos, denominado de grupo A, fez uma adaptação bastante simples no jogo "Fazendo Compras" (fig. 1) para viabilizar a compreensão dos conceitos físicos dos conteúdos de MRU e MRUV e estimular o raciocínio. Esse jogo é originalmente composto de um tabuleiro, um dado, personagens, quatro carrinhos e uma folha com as regras. Ele pode ser jogado por até quatro participantes.

Figura 1: a) Jogo de tabuleiro "Fazendo compras"; b) Alunos do EM testando o jogo.
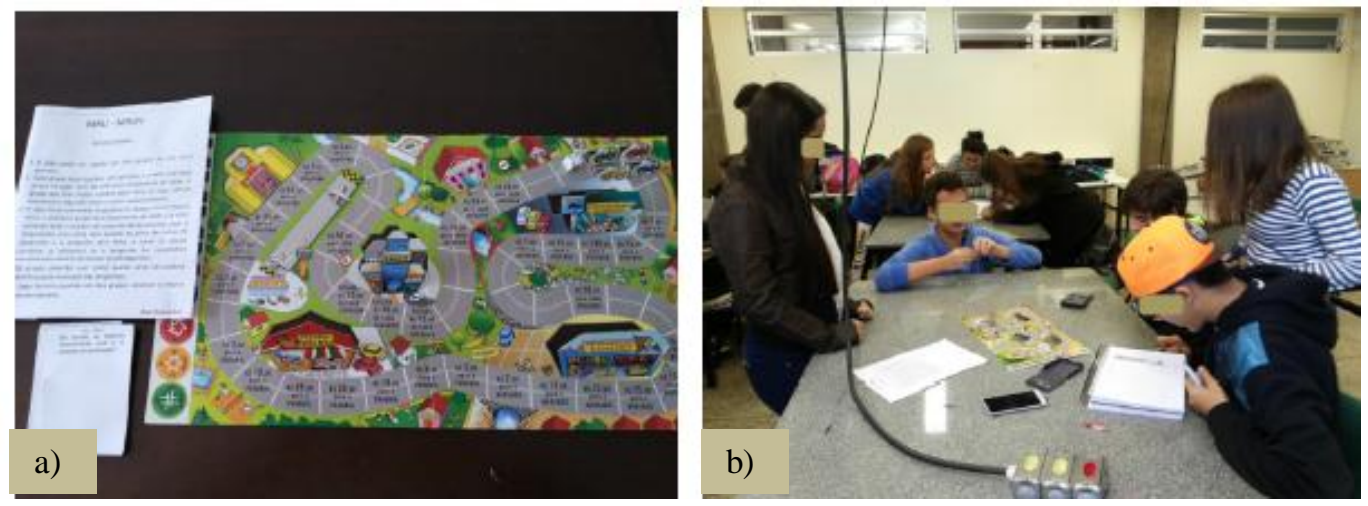

Fonte: Acervo da autora

Com a adaptação, foram inseridas questões (cartinhas de perguntas contendo também as respostas), sobre os locais da trajetória que apresentavam textos (desse modo, o texto anterior não atrapalhou o jogo) e um “juiz".

Para jogar, inicialmente cada participante deve escolher um carrinho. O jogo inicia pelo participante que obtiver o maior número ao lançar um dado. Na sequência, o jogador lança o dado e avança o número de casas de acordo com o número obtido no dado. Se na casa em que parar, tiver uma pergunta, ele deve responder. Se acertar 
avança algumas casas, se errar deve retornar à posição anterior. O jogo termina quando um dos participantes completar a trajetória.

Segundo a avaliação (pergunta 6 do questionário) aplicada aos alunos do EM que testaram os jogos, nas regras faltou informar a quantidade de casas a se avançar ou retornar se acertasse ou errasse a questão.

A professora regente também apontou para que seja apresentada separadamente a carta de pergunta e respostas. E destacou a importância do juiz (mediador) no jogo, pois além de conferir as respostas, ajuda também na inclusão social de alunos cegos ou surdos.

Também orientou para que as cartinhas deveriam possuir texto em relevo ou em braile; sugeriu ainda que os jogos que apresentassem cálculos deveriam ser acompanhados de um bloquinho e lápis para a realização dos cálculos; os jogos poderiam ser apresentados dentro de uma embalagem adequada (caixa, sacola etc.) para melhor apresentação do mesmo. Esses comentários foram extensivos a todos os trabalhos.

Vale destacar que os jogos com regras podem constituir um recurso pedagógico eficaz para a aprendizagem dos estudantes, inclusive os que apresentam transtorno de déficit de atenção e hiperatividade (TDAH). Além de contribuir para desenvolver habilidades acadêmicas como leitura, escrita e aritmética, eles colaboram para a melhoria da atenção, da concentração e do autocontrole (ANDRADE, 2014).

\section{JOGO "FÍSICA DO COTIDIANO"}

Esse jogo, cujo nome original era "O trânsito" (fig. 2) pode ser jogado com até quatro jogadores e permite explorar diversos assuntos de Física aplicados ao dia a dia. Ele foi adaptado pelo grupo B e é composto de um tabuleiro, saquinho com números de 1 a 12 e várias cartinhas contendo perguntas de assuntos de Física 1. Esses números correspondem aos estabelecimentos existentes no jogo de tabuleiro.

Deve iniciar o jogo, o jogador que obtiver o maior número no lançamento do dado. Esse participante retira um número do saquinho. O juiz pega a questão correspondente e questiona. Se o jogador acertar ganha três pontos; se errar não pontua. Ganha o jogo, o aluno que primeiro completar 21 pontos, previstos no jogo. 
Figura 2: Jogo de tabuleiro TRÂNSITO. a) O jogo com as adaptações; b) Alunos do EM testando o jogo durante a aula prática no laboratório de Física.
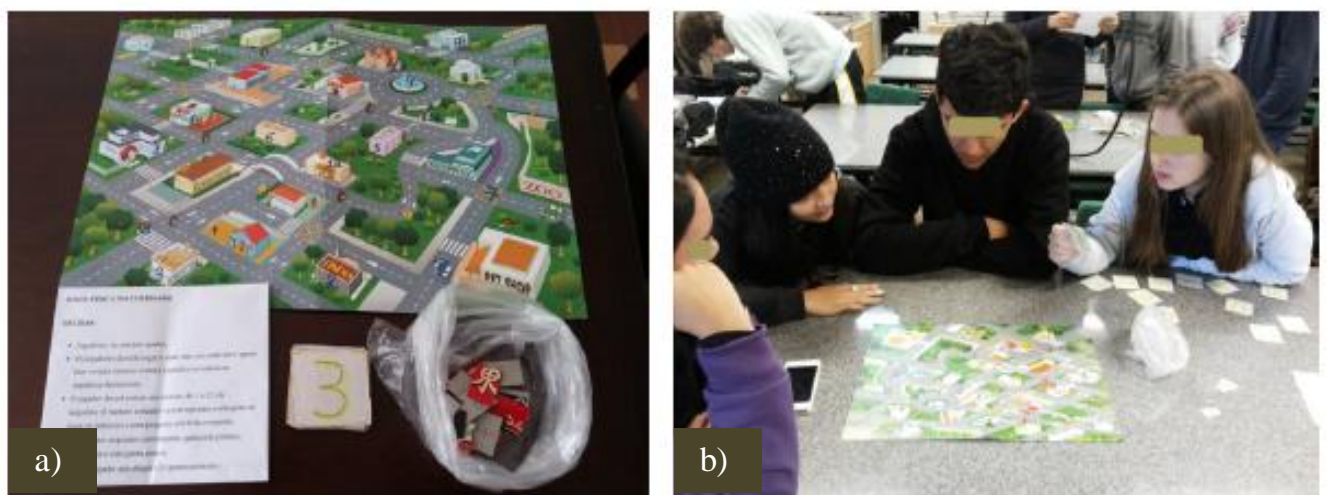

Fonte: Acervo da autora

Nesse jogo, rico em detalhes, pode-se explorar as unidades de medida, os conceitos de referencial, trajetória, deslocamento, caminho percorrido, ou seja, conceitos e aplicações de MRU, MRUV, vetores, ondulatória, óptica entre outros. Podese também fazer a conscientização do jovem para viver em sociedade, respeitando as leis do trânsito, pois buscou-se relacionar a disciplina (Física) com questões do dia a dia, destacando o assunto "trânsito". Em 2011, Fontes e Ferreira também realizaram um projeto interdisciplinar bastante interessante, com alunos do EM, envolvendo o assunto "trânsito" com as diversas disciplinas e constatou como foi importante essa atividade para os alunos, visto que, na fase de juventude, muitas vezes dirigem sem possuírem total conhecimento de segurança e leis do trânsito.

Segundo a avaliação aplicada aos alunos do EM, eles sugeriram que: fosse feita uma tabela para anotar os pontos dos participantes; que se alterasse nas regras a informação "ganhará o jogo quem atingir mais pontos ao final" e não "quem atingir 21 pontos", pois conforme o número de participantes, poderia não chegar a esta pontuação devido ao pouco número de perguntas; inserir mais perguntas no jogo.

Uma sugestão da professora regente é que o jogo, por envolver questões de Física 1, 2 e 3, ficou prejudicado para os alunos de Física 1. Assim, seria melhor aproveitado para os alunos de Física 3. Outra sugestão é que fossem separadas as cartinhas contendo as perguntas das com as respostas, para evitar que o jogador da vez não pudesse ler a carta, pois já saberia a resposta. Para explorar melhor o jogo, poderia 
ser trabalhada, de forma interdisciplinar, a importância de cada estabelecimento dentro de uma cidade e a distribuição espacial da cidade (ruas, praças, sinaleiros, divisões etc.).

Além dos conteúdos abordados, como sugestão também poderiam ser exploradas as medidas de comprimento (transformações, unidades etc.), que fazem parte do capítulo 1 dos livros (introdução a Física); e no capítulo 2, introdução ao estudo dos movimentos, trabalhando os conceitos de referencial, deslocamento, distâncias percorridas por um carro, tipos de movimento (progressivo ou retrógrado), velocidade média, tomando como exemplo um carro partindo do shopping indo para o cinema, ou outro estabelecimento. E dessa forma, escrever as funções horárias para cada móvel. Montar situações de encontro onde cada carro passará por cruzamentos diferentes até chegar ao local do encontro.

Os alunos gostaram muito desse jogo, pois viram aplicações da Física no cotidiano e as regras são claras e fáceis de jogar.

Este jogo, por se parecer muito com uma maquete, possibilitou explorar vários conceitos, assim como feito por Munhoz; Bueno (2015), que visualizaram que o estudo da Cinemática através de maquetes corrobora para um estudo de Física contextualizado, pois possibilita a correlação entre cotidiano e conhecimento científico. Além disso, proporciona um bom rendimento às aulas pela visualização do conteúdo abordado, apreensão e identificação dos objetos, surgimento de questionamentos e interesse voltados aos elementos representados nas maquetes, permitindo ao aluno maior participação no seu processo de ensino-aprendizagem.

Como as questões desse jogo envolvem situações cotidianas, elas tendem a fazer com que os jogadores desenvolvam a capacidade de imaginar a situação problema apresentada pela questão, à medida que eles se sentem motivados e desafiados pelo jogo.

\section{JOGOS “A ILHA DO TESOURO” E “CAÇA AO TESOURO”}

O jogo "A ilha do tesouro" foi adaptado pelo grupo C e o jogo "Caça ao tesouro" foi adaptado pelo grupo D. O tabuleiro e as peças são os mesmos. Com as adaptações feitas pelos alunos (fig. 3), puderam ser explorados os conteúdos de queda livre, dinâmica, movimento oblíquo, cinemática e MCU no jogo “A caça ao tesouro", e 
no jogo "A ilha do tesouro" puderam ser trabalhados os conteúdos de transformações de unidades de medida, MRU e dinâmica.

Tanto um quanto o outro podem ser jogados por até seis participantes. Inicialmente embaixo de cada carta das ilhas (que serão posicionadas sobre as figuras no tabuleiro), será escondida outra carta, onde somente uma delas tem a figura de um baú de tesouro. Ganha o jogo, o aluno que encontrar o baú. Iniciará o jogo, o jogador que tirar o maior número no lançamento do dado.

O jogador desloca-se no tabuleiro, seguindo o número de casas que sair no dado. Ele tem que ir sempre em direção às ilhas, passando em todas, uma por vez. No tabuleiro existem vários $\mathrm{X}$, onde cada $\mathrm{X}$ equivale a uma pergunta. Se o jogador acertar, avançará 3 casas, se errar, voltará à posição anterior.

Figura 3: a) Jogo a ilha do tesouro; b) alunos do Ensino Médio testando o jogo.
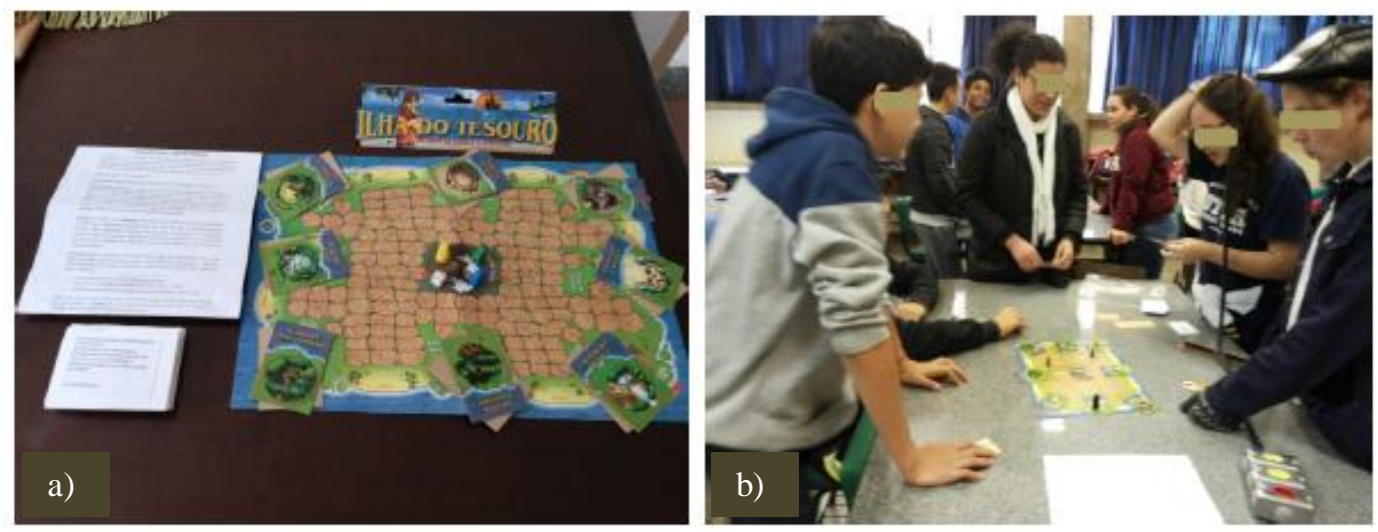

Fonte: Acervo da autora

Segundo sugestões dos alunos do EM, deve-se colocar alguns $\mathrm{X}$ de pergunta em pontos estratégicos nos dois jogos; além disso, no jogo "A ilha do tesouro" há questões mal formuladas e falta uma resposta. Também sugerem que sejam inseridas mais questões e que as regras devem ser claras.

De acordo com Miranda (2001), o jogo didático também acaba contribuindo para o desenvolvimento de outros aspectos, onde vários objetivos podem ser atingidos, relacionados à: cognição; afeição; socialização; motivação; e à criatividade. 
Ensino, Saúde e Ambiente - V9 (3), pp. 226-248, Dez. 2016

\section{JOGO "DAMA VETORIAL"}

O jogo de Dama foi adaptado pelos alunos do grupo E, para que pudessem ser exploradas as coordenadas vetoriais de um vetor em um plano (fig. 4), e foi nominado de "Dama Vetorial".

O jogo funciona como uma partida de dama normal, pela forma como as peças são colocadas no tabuleiro. Após definido quem começa o jogo (por meio de "par ou ímpar"), o jogo começa da seguinte forma: o jogador deve passar as coordenadas em termos de vetores unitários para o jogador adversário se deslocar no tabuleiro; se este errar, a peça sai. Assim, sucessivamente, ganha o jogo quem tiver mais peças ao final.

Figura 4: a) Jogo dama vetorial; b) alunos do EM testando o jogo.
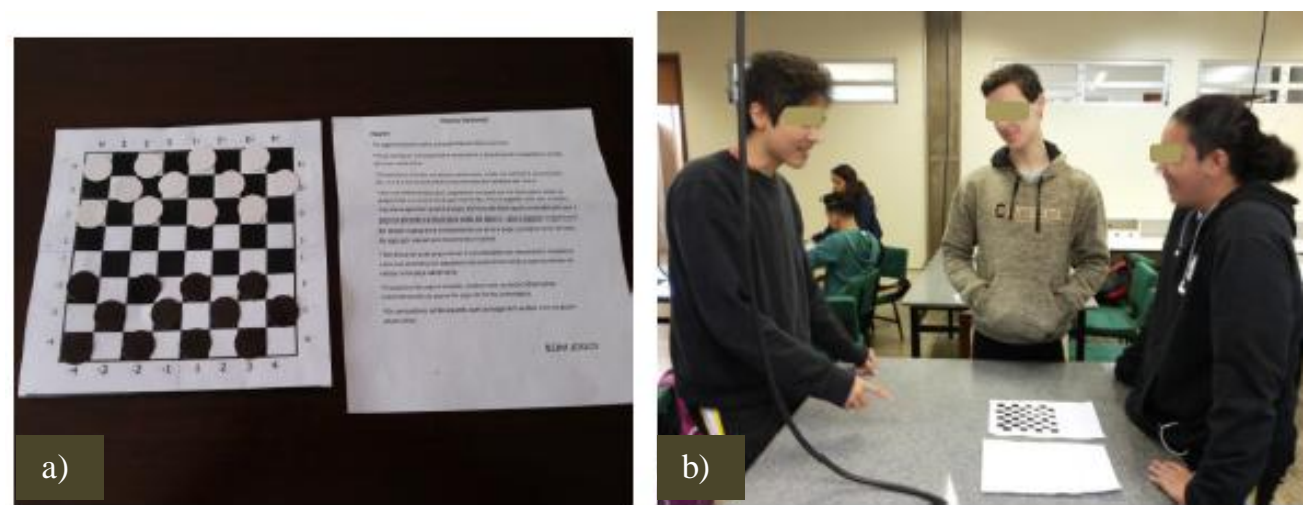

Fonte: Acervo da autora

Comentários dos alunos: Colocar mais informações nas regras dos jogos.

Sugestão da professora: o jogo deveria trazer cartas com as coordenadas (vetores unitários), assim, conforme a vez, o jogador desviraria a carta e seguiria as coordenadas; também deveriam ser inseridos eixos x e y no tabuleiro.

De um modo geral, as turmas participaram ativamente das atividades (fig. 5), que foram distribuídas em cinco bancadas, de maneira que, ao terminar um jogo, o grupo deveria se dirigir a outra bancada que continha outro jogo, para acompanhar os demais.

Figura 5: Alunos do EM durante a realização da atividade 


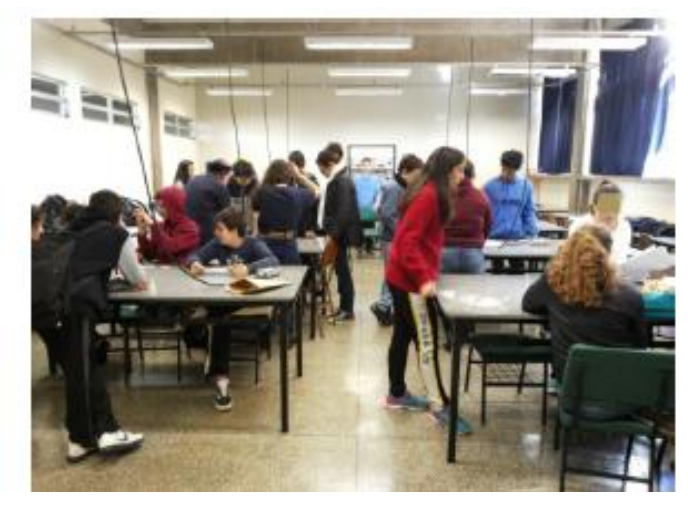

Fonte: Acervo da autora

Alguns depoimentos dos alunos que surgiram no término da atividade foram:

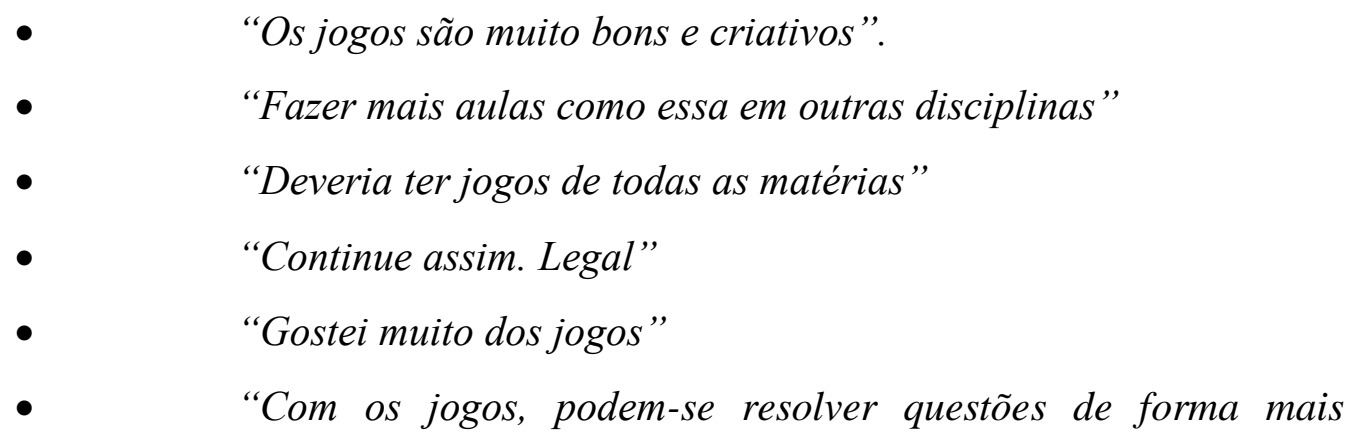

descontraída”.

Ao término da realização das atividades, foi aplicado um questionário nas duas turmas. A questão 1, referia-se a conteúdos abordados nos jogos. De um modo geral, os alunos das duas turmas conseguiram identificar diversos conteúdos contidos nos jogos, conforme apresentados no quadro 1.

Quadro 1: Primeira pergunta do questionário aplicado aos alunos e síntese das respostas.

\begin{tabular}{|l|l|}
\hline \multicolumn{2}{|c|}{ 1- O que havia de conteúdos de Física nesses jogos? } \\
\hline Fazendo Compras & MRU, MRUV, Transformações de unidades. \\
\hline $\begin{array}{l}\text { A física do } \\
\text { cotidiano }\end{array}$ & $\begin{array}{l}\text { MRU, MRUV, Óptica, Acústica, Eletromagnetismo, } \\
\text { Cinemática, Queda livre, Termologia. }\end{array}$ \\
\hline Caça ao tesouro & $\begin{array}{l}\text { Queda livre, Leis de Newton, Movimento oblíquo, } \\
\text { MRUV, Cinemática, MCU. }\end{array}$ \\
\hline Ilha do tesouro & $\begin{array}{l}\text { Definições, Transformações de unidades, Unidades } \\
\text { de medida, Força, Leis de Newton, MRU. }\end{array}$ \\
\hline Dama vetorial: & Vetores (coordenadas). \\
\hline
\end{tabular}


Ensino, Saúde e Ambiente - V9 (3), pp. 226-248, Dez. 2016

O jogo "Dama vetorial" só foi aplicado para a turma de Física 2, pois a de Física 1 ainda não havia estudado o conteúdo de vetores.

Na questão 2, foi perguntado aos alunos, para que servem esses jogos?

As respostas mais comuns às duas turmas foram:

- 44,8\%: Reforçar/ revisar conteúdos já vistos, de uma forma divertida, criativa, e mais dinâmica.

- 20,7\%: Avaliar o conhecimento do aluno.

- 13,8\%: Introduzir um conteúdo e reforçar conhecimentos gerais da Física.

Também surgiram respostas como:

- 6,9\%: Mostrar como a Física está em nosso cotidiano e nem percebemos (aplicações);

- $\quad 6,9 \%$ : Aprender Física brincando;

- Mostrar aplicações da Física de uma forma bem dinâmica;

- $\quad$ O jogo serve para atrair os alunos aos conteúdos de Física, pois de uma forma divertida, os alunos praticam tais conteúdos;

- $\quad$ Despertar o interesse pela Física e promover um ensino diferente;

- São boas ferramentas de avaliação de conhecimento.

As respostas indicam que o trabalho foi bastante positivo e aceito pelos alunos.

Ao perguntar-lhes, na questão 3, se obtiveram êxito nos jogos, somente $32,8 \%$ disseram que sim (onde desses, 20,7\% eram da turma de Física 2). Os outros alunos se dividiram em razoável e não. O resultado indica que pelo fato de alguns jogos misturarem conteúdos de Física 1, 2 e 3, dificultou os acertos dos alunos e indicou também certa dificuldade com os conteúdos de Física.

Uma aluna respondeu que: 
Ensino, Saúde e Ambiente - V9 (3), pp. 226-248, Dez. 2016

"Não, pois são perguntas difíceis, mas aprendi bastante física com os amigos durante o jogo".

Ou seja, a interação com os colegas proporcionada nessa aula, fez com que a aluna aprendesse alguns conceitos físicos, indicando que o recurso é válido.

Ao perguntar-lhes, na questão 4, se já haviam utilizado algum jogo em sala de aula de Física, 43\% dos alunos da turma de Física 2, responderam que sim, indicando que a professora regente, que é a mesma nas duas turmas, trabalha com jogos somente na turma de Física 2, talvez devido ao grau de maturidade da turma.

A questão 5 era sobre como foi a aula de hoje, onde todas as respostas foram satisfatórias. As respostas que mais apareceram nas duas turmas foram:

(17) Diferente e interativa;

(11) Legal/ Boa

(8) Muito legal, divertida, produtiva, interessante;

(8) Top master

(7) Dinâmica e bem interessante

As respostas indicam, de modo geral, que valeu a pena aplicar aos alunos um recurso didático diferente, pois foi muito produtivo e teve excelente aceitação.

A questão 6 pedia sugestões para a melhoria dos jogos. As respostas foram apresentadas anteriormente no texto dos jogos.

A adaptação desses jogos representou uma atividade significativa para a formação dos licenciandos; envolveu um processo de preparação, caracterizado por pesquisas e discussões relacionadas ao papel do lúdico no ensino.

A terceira etapa baseou-se nas orientações de Pereira, Altoé e Neves (2009), que reforçam que nos cursos de formação continuada de professores, os jogos podem ser trabalhados apresentando-os como uma prática pedagógica alternativa, tornando-se mais um recurso que o professor poderá utilizar em sala de aula ou fora dela, abordando também a temática sobre o lúdico e os jogos educativos no ensino-aprendizagem; e com ênfase no desenvolvimento de materiais didático-pedagógicos, ou exclusivamente, 
jogos educativos; por isso, a terceira etapa de aplicação dos jogos ocorreu durante uma oficina para professores do Ensino Básico.

A atividade identificou que, dentre 18 professores da disciplina de Física presentes, somente um já havia utilizado jogos didáticos em suas aulas como ferramenta facilitadora do processo de ensino-aprendizagem, e um dos fatores levantados para justificar a falta de uso de jogos foi a escassez de material na escola. Quando se buscou levantar o uso de jogos didáticos, todos justificaram que nunca utilizaram e não tinham tempo hábil para confeccionar o mesmo. Ao apresentar a alternativa de adaptação do jogo, todos gostaram, e disseram não ter conhecimento disso, mas indicaram que iriam comprar e adaptar jogos, visto a facilidade, o preço e a utilidade dos mesmos.

Em consonância com Costa; Verdeaux (2016), à medida que os professores conhecem novas experiências didáticas para a sala de aula, como a aplicação de jogos, este processo motiva-os a buscar temas dentro do cotidiano de seus estudantes a fim de elaborarem aulas mais dinâmicas e que permitam uma real compreensão dos conteúdos ensinados.

Após a realização da terceira etapa, foi dado um feedback aos licenciandos. Esse feedback foi muito importante, pois a professora regente pode explicar aos acadêmicos sobre os cuidados na hora de elaborar um material didático (PEREIRA; ALTOÉ; NEVES, 2009), pensando a quem se destina e a finalidade que se quer dar.

Com o feedback dado aos alunos, supõe-se que os mesmos terão maiores oportunidades de sucesso na realização de outra atividade similar (enquanto licenciandos ou docentes), pois o uso de feedbacks como estratégia de ensino viabiliza um contato maior com os conhecimentos a serem assimilados (COSTA; VERDEAUX, 2016).

Uma sugestão de adaptação de jogos, que não foi trabalhada nessa PCC, foi o jogo da memória. Esse jogo vem, geralmente, em uma caixa e apresenta peças em madeira com seus pares correspondentes. Para fazer a adaptação, o professor, após a elaboração das questões, imprime as questões e cola sobre os bloquinhos de madeira.

Uma aplicação possível, por exemplo, seria a de relacionar as grandezas físicas com as unidades de medida; História da Física (os cientistas como construtores de leis/ “descobertas”); gráficos com suas funções (explicações) entre outros. Esse jogo (fig. 6) 
poderia estimular a memória dos estudantes e seria utilizado da seguinte forma: inicialmente as peças seriam misturadas, e, após todos olharem suas localizações, elas seriam viradas.

Figura 6: a) Jogo da memória original, e ao lado (b) uma adaptação ao jogo através da História da Física (Físicos, suas épocas e contextos, e suas principais “descobertas”).
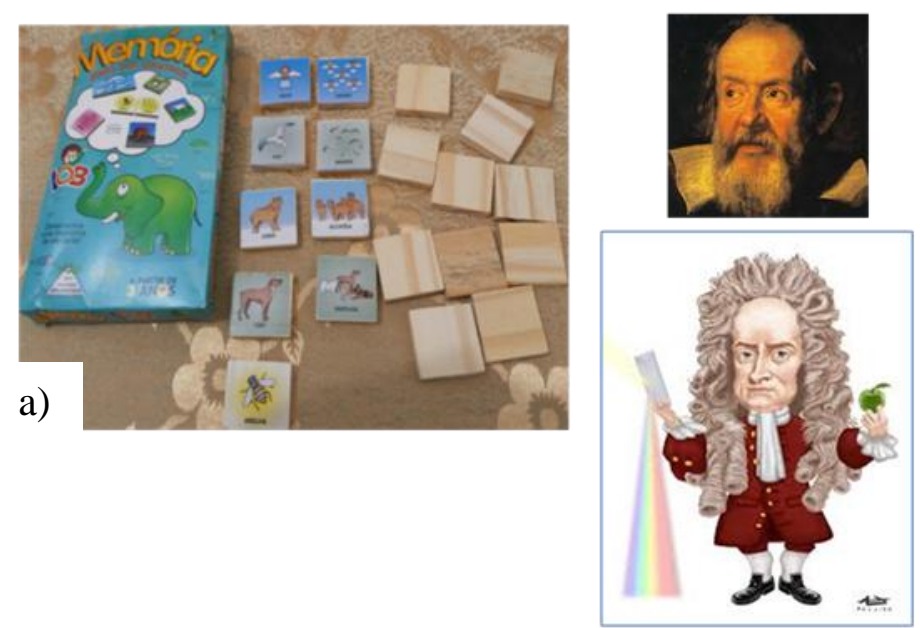

Galileu Galilei (1564- 1643), Galilei considerado um dos fundadores do método experimental e da ciência moderna. Suas principais contribuições à física dizem respeito ao movimento dos corpos e à teoria da cinemática. Luneta.

Isaac Newton (1643-1727)

- Série de potência de um binômio, que hoje é conhecido pelo nome de binômio de Newton; - A criaçăo e desenvolvimento do cálculo diferencial e cálculo integral;

- 0 estudo sobre os fenômenos óticos que possibilitaram a elaboraçăo da teoria sobre a cor dos corpos;

- O estudo das leis dos movimentos, lançando as bases da Mecânica;

- $O$ desenvolvimento das primeiras ideias sobre a Gravitaçăo Universal.

Albert Einstein (1879-1955).

Relatividade restrita: as medições do tempo e da distância dependem do movimento relativo dos observadores, aplicações em satélites, GPS e outras tecnologias. Relatividade geral: a força da gravidade é interpretada como um efeito da curvatura do espaço-tempo.

Efeito fotoelétrico Einstein constatou que a luz não era uma onda contínua, como se

b)

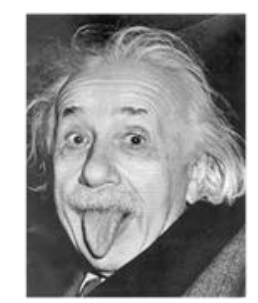
pensava, mas pequenos conjuntos de fóton que estimulam certos meta
elétrons, gerando energia.

\section{Fonte: Autoria própria}

O primeiro jogador vira uma carta e após outra para localizar seu par. Se acertar continua e se errar, passa a vez para o próximo jogador. Ganha quem conseguir juntar mais peças.

\section{CONSIDERAÇÕES FINAIS}

Não restam dúvidas das dificuldades encontradas no ensino de Física, na educação básica da rede pública. O eco desses desafios alcançaram os acadêmicos de Licenciatura em Química. Durante o percurso desses licenciandos na disciplina de Física 1, foi possível identificar seus receios sobre as formas de lecionar. Essa atmosfera 
contribuiu para a organização de uma atividade, em que esses futuros professores tiveram a oportunidade de adaptar jogos didáticos para o uso nas aulas de Física do EM. E isso de modo a poder utilizar o modelo para aplicação em outras disciplinas. Esse foi o primeiro material didático que os alunos tiveram contato para o ensino da disciplina Física 1.

Com a aplicação dos jogos aos alunos do EM, percebeu-se que os jogos são realmente uma ferramenta muito importante para o processo de ensino-aprendizagem. Entretanto, apesar dos jogos serem bem recebidos pelos alunos, houve algumas dificuldades na compreensão das regras de alguns dos jogos. Isso trouxe a percepção de que ainda falte a parte dos acadêmicos a experiência e didática para elaborar o material didático. Contudo, entende-se que isso seja normal no processo de formação, ao passo que a relevância desta experiência reside justamente na conscientização dos futuros professores.

Foi identificada também a ausência de materiais didáticos nas aulas dos professores pertencentes à rede pública de Educação Básica na disciplina Física. Para tanto, essa atividade estimulou-os para o uso de formas alternativas de adaptação de materiais para finalidades didáticas que visem tornar as aulas mais produtivas e prazerosas. A experiência mostrou que é possível encontrar materiais bons e baratos em lojas populares e adapta-los para a sua disciplina, sendo muito simples e de fácil aquisição.

A atividade foi muito interessante, pois, teve seu início, meio e fim. Iniciou com a adaptação dos jogos pelos acadêmicos, seu meio foi a aplicação para os alunos do ensino médio, e seu fechamento se deu no retorno que a professora regente deu aos licenciandos após os alunos do EM testarem (avaliarem) os jogos e com a opinião dos professores da rede pública a respeito dos jogos adaptados, após uma atividade de formação continuada. A experiência foi de extrema importância para a formação inicial dos futuros docentes.

Tendo em vista a aceitação dos jogos por parte dos estudantes e dos professores do EM, e, tendo identificado que os licenciandos e os professores do EM não sabiam trabalhar com os jogos, sugerimos, pela sua aplicabilidade e aceitação, que sejam inseridos atividades com jogos didáticos (adaptados ou confeccionados pelos próprios acadêmicos), nos cursos de licenciatura e também na formação continuada. 
A atividade de PCC escolhida foi muito interessante para todos os envolvidos. Primeiro pela escolha de um recurso pedagógico que os licenciandos não haviam tido contato durante sua vida escolar, mas que todos gostaram da ideia; segundo porque o trabalho foi testado por alunos do EM em que foram levantadas impressões e sugestões; terceiro porque também teve a opinião de professores de Física da rede pública, que disseram ter gostado muito da ideia e ficaram de adaptar para as suas aulas.

Por meio da análise dos materiais e aplicação, foi possível sensibilizar profissionais da educação para o potencial didático de práticas de elaboração de jogos didáticos para os alunos, como ferramenta lúdica e interativa que visam complementar conhecimentos. Possivelmente, essa experiência corroborou para que licenciandos e professores façam uso dessa prática de elaboração e uso de jogos didáticos em sua prática docente.

Todavia, ressalta-se que nesse processo pedagógico não se mostra como demérito o uso da adaptação de um jogo existente em relação à construção de um jogo didático novo para o ensino de Física. Ora, o que está em questão é o alcance da aprendizagem, de modo que tanto uma proposta quanto a outra possuem o mesmo objetivo; de estimular o aluno, abranger os conteúdos e, assim, proporcionar uma melhoria no processo de ensino e aprendizagem.

\section{REFERÊNCIAS}

ANDRADE, R. Jogos para aumentar a concentração. Revista Educação. São Paulo: Segmento, Ano 18. N 209 p. 13, 2014.

COSTA, T. M; VERDEAUX, M. F. S. Gamificação de materiais didáticos: Uma proposta para a aprendizagem significativa da modelagem de problemas físicos. Revista Experiências em Ensino de Ciências. V.11, n.2, p.1-46, 2016.

UTFPR. Universidade Tecnológica Federal do Paraná. Diretrizes curriculares para os cursos de graduação. Curitiba, 2012. Disponível em: $<$ http://www.utfpr.edu.br/estrutura-universitaria/proreitorias/prograd/legislacao/00812DiretrizesGraduacaoUTFPRVersaoFinalpagina.pdf> Acesso em: 30 março 2016.

FERREIRA, J. M. H.; OLIVEROS, M. C.; CÂMARA, A. T.; CAZUZA, E. P.; LABRE, I. O. A.; RIBEIRO, J. K.; SILVA, J.; JULIÃO, W. S. Elaboração de jogos didáticos no PIBID em dupla perspectiva: formação docente e ensino de Física. Anais VIII EMPEC, Campinas, 2011. Disponível em: 
<http://www.nutes.ufrj.br/abrapec/viiienpec/resumos/R0624-2.pdf $>$. Acesso em: 03 setembro 2015.

FONTES, A. S.; FERREIRA, C. Educação para o trânsito: um estudo interdisciplinar para o ensino de ciências na escola básica. Ciência em Tela. V4, n.2, 1-11, 2011.

GOMES, R. R.; FRIEDRICH, M. A. Contribuição dos jogos didáticos na aprendizagem de conteúdos de Ciências e Biologia. In: EREBIO,1, Rio de Janeiro, 2001, Anais, Rio de Janeiro, p. 389-92, 2001.

LEGEY, A. P.; MOL, A. C. A.; BARBOSA, J. V.; COUTINHO, C. M. L. M. ALEXANDRIA Revista de Educação em Ciência e Tecnologia, Florianópolis, v. 5, n. 3, p. 49-82, 2012. Disponível em:

http://alexandria.ppgect.ufsc.br/files/2012/11/AnaLegey.pdf>. Acesso em: 20 fevereiro 2015.

MIRANDA, S. No Fascínio do jogo, a alegria de aprender. Ciência Hoje, Rio de Janeiro, v. 28, p. 64-66, 2001.

MESQUITA, L.; MONTEIRO, M. A. A.; SENA, G. J.; NINOMIYA, M. P.; COSTA, C. A. Education for Energy Efficiency through an Educational Game. 2013 IEEE Frontiers in Education Conference (FIE), Oklahoma City, OK, 535-540, 2013.

MOREIRA, M. A. Uma Abordagem Cognitivista ao Ensino da Física. Porto Alegre: Ed. da Universidade, UFRGS, 1983.

MUNHOZ, K. G.; BUENO B. S. Uso de maquetes no ensino de Física: uma experiência metodológica eficiente na construção de aprendizagens significativas. Revista Eventos Pedagógicos. V. 6, n. 2 (15 ed.), p. 301-310, jun/jul. 2015.

NASCIMENTO, T. L. Repensando o Ensino da Física no Ensino médio. Monografia. Curso de Física. Universidade Estadual do Ceará. Centro de Ciências e Tecnologia. Fortaleza, 2010. Disponível em:

<www.uece.br/fisica/index.php/arquivos/doc_download/75>. Acesso em: 14 outubro 2015.

PARIS, T. N. S. T. Enhancing Grammar Using Board Game. Procedia - Social and Behavioral Sciences, V. 68, p. 213-221, 2012.

PEREIRA, R. F.; FUSINATO, P. A.; NEVES, M. C. D. Desenvolvendo um jogo de tabuleiro para o ensino de física. In: Encontro Nacional de Pesquisa em Educação e Ciências, Anais VII ENPEC. p.1-12. 2009. Disponível em:

$<$ http://posgrad.fae.ufmg.br/posgrad/viienpec/pdfs/1033.pdf>. Acesso em: 03 setembro 2015.

PEREIRA, R. F.; FUSINATO, P. A.; NEVES, M. C. D.; BATISTA, M. C.

LUDOASTRONOMIA: Um jogo de tabuleiro para o ensino de Astronomia. Anais do XIX SNEF, Manaus, 2011. 
RAHAL, F. A. S.; LUZ, A. R. Jogos didáticos no ensino de física: Um exemplo na termodinâmica. In: XVIII Simpósio Nacional de Ensino de Física, 2009, Vitória-ES. Disponível em:

〈http://www.cienciamao.usp.br/dados/snef/_jogosdidaticosnoensinode.trabalho.pdf $>$. Acesso em: 02 setembro 2015.

RAMANI, G. B.; SIEGLER, R. S. Promoting Broad and Stable Improvements in LowIncome Children's Numerical Knowledge Through Playing Number Board Games.

Child Development, 79, Number 2, p. 375-394, 2008.

SAVI, R.; VON WANGENHEIM, C. G.; ULBRICHT, V.; VANZIN, T. Proposta de um modelo de avaliação de jogos educacionais. RENOTE, v. 8, n.3, dezembro de 2010.

SILVA, H. A. O uso do jogo no ensino de Física com foco nas competências e habilidades exigidas pelo novo ENEM. Dissertação de mestrado. Programa de Pósgraduação em Ensino de Ciências e Matemática. Centro Federal de Educação Tecnológica Celso Suckow da Fonseca, Rio de Janeiro, 2012.

SILVA, L. G. F.; LOPES, R. L.S. U.; SILVA, M. F.; TRENNEPOHL JR, W. Formação de professores de Física: experiência do Pibid*. RBPG, Brasília, v. 9, n. 16, p. 213-227, abril de 2012.

SOUZA NETO, S; SILVA, V. P. Prática como componente curricular: Questões e reflexões. Rev. Diálogo Educ., Curitiba, v.14, n.43, p. 889-909, 2014.

VIRVOU, M.; PAPADIMITRIOU, S. Use of digital 'Guess Who Board Game' in teaching English. Information, Intelligence, Systems and Applications, IISA 2014, The 5th International Conference on Information, Intelligence, Systems and Applications, Chania, 2014, p. 439-443.

YAMAZAKI, S. C.; YAMAZAKI, R. M. O. Jogos para o ensino de física, química e biologia: elaboração e utilização espontânea ou método teoricamente fundamentado? R.B.E.C.T., vol 7, num.1, jan-abr.2014. Disponível em: $\langle$ https://periodicos.utfpr.edu.br/rbect/article/viewFile/1310/1225>. Acesso em: 03 setembro 2015. 